\title{
Investigations on the Effects of Dietary Essential Oils and Different Husbandry Conditions on the Gut Ecology in Piglets after Weaning
}

\author{
P. Janczyk, ${ }^{1,2}$ R. Pieper, ${ }^{1,3}$ V. Urubschurov, ${ }^{1}$ K. R. Wendler, ${ }^{4}$ and W. B. Souffrant ${ }^{1}$ \\ ${ }^{1}$ Research Unit “Oskar Kellener”, Research Institute for the Biology of Farm Animals, Wilhelm-Stahl-Allee 2, \\ 18196 Dummerstorf, Germany \\ ${ }^{2}$ Institute of Veterinary Anatomy, Faculty of Veterinary Medicine, Freie Universität Berlin, Koser straße 20, 14195 Berlin, Germany \\ ${ }^{3}$ Institute of Animal Nutrition, Faculty of Veterinary Medicine, Freie Universität Berlin, Bruemmer straße 34, 14195 Berlin, Germany \\ ${ }^{4}$ Delacon Biotechnik GmbH, Weissenwolff straße 14, A-4221 Steyregg, Austria
}

Correspondence should be addressed to W. B. Souffrant, wbsouffrant@fbn-dummerstorf.de

Received 31 July 2008; Revised 25 December 2008; Accepted 5 February 2009

Recommended by Effie Tsakalidou

Essential oils (EO) are being considered as possible alternatives to in-feed antibiotic growth promoters in pig nutrition. The effects of an EO mixture consisting of limonene, eugenol and pinene (10.0, 2.0, and $4.8 \mathrm{mg} / \mathrm{kg}$ diet, resp.) on gut physiology and ecology were studied in piglets. The experiment was conducted at low (commercial farm) and high hygienic conditions (experimental farm), to elucidate interactions between EO supplementation and husbandry methods. Piglets were weaned at 28 days of age, when they were offered either a control diet (C) or C with EO. Four piglets were sacrificed in each group on day 29, 30,33 and 39. Digesta from the third distal part of the small intestine and from the colon were sampled and analysed for $\mathrm{pH}$, dry matter, lactic acid, short chain fatty acids and ammonia concentrations. Enterobacteria, enterococci, lactobacilli and yeast counts were obtained by plating. Genomic DNA was extracted from digesta and polymerase chain reaction-denaturing gradient gel electrophoresis was performed. Individual microbial communities were identified at each farm. Age affected the intestinal parameters. No effects of the EO with exception for a significant reduction in colon bacterial diversity at 39 days of age could be recorded at experimental farm.

Copyright (C) 2009 P. Janczyk et al. This is an open access article distributed under the Creative Commons Attribution License, which permits unrestricted use, distribution, and reproduction in any medium, provided the original work is properly cited.

\section{Introduction}

Weaning of piglets is associated with very severe stress. Abrupt removal of the young piglets from the dam, mixing of different litters, dietary changes (from a milk to a cerealbased diet), and contact with unknown bacteria not only result in changes in the intestinal microbial community but also suppress the immune system and increase the prevalence to intestinal pathogens. In combination with other factors, such as changes in intestinal morphology and enzyme activity [1-3], this sets the scene for the development of postweaning diarrhoea with resultant performance losses.

Therefore, prophylactic in-feed antibiotics have been used for decades to ameliorate the postweaning reduction in productivity. Since the beginning of 2006, in-feed antibiotics used in pig production have been banned in the European Union. In order to sustain high productivity in pork production, researchers have searched for alternatives such as probiotics, prebiotics, and phytobiotics which might have growth promoting effects similar to in-feed antibiotics.

Essential oils (EO) are volatile, aromatic mixtures, consisting principally of terpenes and phenylpropane derivatives. They are present in many plant tissues, where their primary function is to protect the plant against bacteria and parasites. The composition of essential oils may vary depending on species [4], geographical origin, or vegetative stage [5]. Many essential oils have strong antibacterial effects in vitro [6]. Active components of essential oils are known to have antioxidative [7] and anti-inflammatory effects [8, 9]. Feeding diets supplemented with plant extracts can influence 
the microflora in the digestive tract of early weaned piglets by increasing the number of lactobacilli and the ratio of lactobacilli and enterobacteria in the jejunum and caecum $[10,11]$. Furthermore, positive effects on the nutrient digestibility $[12,13]$ and growth performance [13] in piglets have been reported.

In the present study, limonene, eugenol, and pinene were chosen to be combined in a feed additive for weaned piglets. These substances are well known for their antibacterial properties $[14,15]$. They were selected because of known antioxidative [7] and anti-inflammatory [16], but also for their immunomodulatory [17] and relaxant and spasmolytic effects $[18,19]$. All of these effects might be especially beneficial to piglets during the stressful weaning period.

The effect of growth promoting feed additives may depend on hygienic conditions of the farm. Only small effects might be obtained in situations with high hygienic status, while the potential for performance improvements may be more pronounced under less optimal (i.e., field) conditions. Therefore, the aim of this study was to investigate the effects of essential oils in the starter diet on development of gut ecophysiology of piglets after weaning under different hygienic conditions.

\section{Material and Methods}

2.1. Animals and Housing. The study comprised two experiments. One experiment was carried out at the experimental pig farm (EF) of the Research Institute for the Biology of Farm Animals Dummerstorf, Germany and the other at a commercial farm (CF). Natural light regime and humidity (50-60\%) were common for both facilities. No antibiotics (for prophylactic or therapeutic reasons) were given to the animals at either facility.

Piglets of German Landrace sows in 2nd to 6th parity were used for the experiment. To reduce the genetic difference between litters, all piglets at both facilities had one father boar. Piglets were weaned at 28 days of age. The whole litter from one dam (8-11 piglets of both sexes) was allocated to a pen of $4.38 \mathrm{~m}^{2}$ at EF and $4.20 \mathrm{~m}^{2}$ at CF. Eight litters per farm were included in the experiment. The experiments were approved by the Ethical Committee of the Ministry of Nutrition, Agriculture, Forestry and Fishery MecklenburgVorpommern, Germany.

2.2. Diets and Feeding. At each farm, four litters were fed a starter diet (C), and four other litters received the starter diet containing $0.04 \%$ of the (EO) mixture starting at weaning (28 days). Composition of the diets and calculated nutrients are shown in Table 1. The essential oil mixture contained $25 \mathrm{~g}$ limonene, $5 \mathrm{~g}$ eugenol, and $12 \mathrm{~g}$ pinene per $\mathrm{kg}$ product on organic and inorganic carriers (provided by Delacon Biotechnik GmbH; Austria). Diets and water were available ad libitum. Staffing restrictions at the commercial farm meant that it was impossible to regularly weigh the animals, and record feed intake accurately, there. Therefore, body weight (BW) of the pigs from CF was recorded only just before euthanasia, and no feed conversion ratio (FCR) was calculated. At EF, all piglets were weighed at weaning, and the FI in each pen was recorded daily to calculate the FCR.

2.3. Sampling and Chemical Analyses. One piglet was considered a replication unit. Four piglets per treatment group, one out of each pen, were taken at random 1, 2, 5, or 11 days after weaning (at 29, 30, 33, and 39 days of age, resp.) to provide samples. All piglets were sacrificed with an intracardial injection of T61 (Intervet, Unterschleißheim, Germany) after collecting of blood samples. Small intestine (SI) and colon were dissected. The SI was divided into three equal parts, and contents from the distal part and from the colon were collected for chemical and bacteriological analyses and genomic DNA extraction.

Intestinal contents were analysed for $\mathrm{pH}$, dry matter (DM), lactate (LA), ammonia, and short chain fatty acids (SCFAs). $\mathrm{pH}$ was measured with an inoLab $\mathrm{pH}$ Level 1 meter (WTW, Weilheim, Germany). DM was determined after drying for 24 hours at $60^{\circ} \mathrm{C}$ followed by 3 hours at $105^{\circ} \mathrm{C}$. For other chemical analyses, each digesta sample was diluted with water (ratio $1: 3$ ), homogenized and centrifuged at $4500 \mathrm{rpm}$ for 10 minutes at room temperature (rt). The supernatant was used for further analyses. LA concentration was determined calorimetrically after heat precipitation with concentrated sulphur acid in the presence of calcium hydroxide. The absorbance at $565 \mathrm{~nm}$ of the blue-violet colour complex produced following addition of p-hydroxiphenyl was measured on Spectronic 20 Genesys spectrophotometer (Spectronic Instruments, Rochester, NY, USA) using lithium lactate solution as a standard [20]. Ammonia concentration was measured using the Conway microdiffusion assay [21]. For the measurement of SCFA in the digesta, an internal standard SCFA solution was added to the sample. The mixture was centrifuged at $4000 \mathrm{rpm}$ for 20 minutes at rt. The supernatant was collected and centrifuged at $13000 \mathrm{rpm}$ for 10 minutes at rt. SCFAs were then analysed using gas chromatography on GC-17A chromatograph (Shimadzu Deutschland GmbH, Duisburg, Germany) using $25 \mathrm{~m}$ long capillary column of $0.25 \mathrm{~mm}$ diameter [22].

Serum haptoglobin concentration was measured in order to obtain an objective, but indirect indication of contact with provocative antigens. A commercially available competitive enzyme immunoassay (R-Biopharm, Darmstadt, Germany), specific for porcine haptoglobin, was used for analysis. All samples were assayed in duplicate. The limit of detection for this assay was $0.033 \mathrm{mg} / \mathrm{mL}$, and the intra- and interassay coefficients of variation were $2.8 \%$ and $5.2 \%$, respectively.

2.4. Microbiological Analyses. Fresh digesta samples were homogenised, serially diluted, and plated in duplicates onto selective agars (SIFIN, Berlin, Germany). Plates for enumeration of enterobacteria (Violet-Red Bile Dextroseagar) and enterococci (Slanetz and Bartley enterococcus selective agars) were incubated aerobically at $37^{\circ} \mathrm{C}$ for 24 hours. Yeasts were grown for 5 days at $37^{\circ} \mathrm{C}$ on Sabouraud agar. Lactobacilli (LAB) were grown on MRS agar for 72 hours at $37^{\circ} \mathrm{C}$ in anaerobic jars using Anaerocult A (Merck, Germany). Colony forming units (CFU) from the highest 
TABLE 1: Composition of the control and experimental starter diets.

\begin{tabular}{|c|c|c|c|}
\hline Ingredients & $\%$ & Calculated nutrients & $\mathrm{g} / \mathrm{kg}$ (as fed basis) \\
\hline Barley meal & 30.0 & $\mathrm{DM}$ & 888 \\
\hline Wheat meal & 29.7 & $\mathrm{CP}$ & 191 \\
\hline PEF (44\% starch) & 5.0 & Ash & 55 \\
\hline Whey powder & 8.0 & Crude fibre & 34 \\
\hline Wheat bran & 2.5 & Crude fat & 50 \\
\hline Soycomil (soy concentrate) & 4.0 & Starch + sugar & 455 \\
\hline Maize starch ${ }^{1}$ & 4.0 & Lysine & 12.5 \\
\hline Potato protein, purified & 5.0 & Ileal digestable lysine & 11.0 \\
\hline Maize gluten meal & 2.2 & Methionine & 4.4 \\
\hline Sunflower meal & 2.5 & Ileal digestable methionine methionine & 4.0 \\
\hline Limestone & 1.02 & Methionine+Cysteine & 7.8 \\
\hline Mono calcium phosphate & 0.78 & Ileal digestable Met+Cys & 6.6 \\
\hline Trace min.-vit. Premix ${ }^{2}$ & 0.4 & Tryptophan & 2.5 \\
\hline Methionine (99\%) & 0.11 & Ileal digestable tryptophan & 2.1 \\
\hline L-lysine- $\mathrm{HCl}(79 \%)$ & 0.34 & Threonine & 8.0 \\
\hline Tryptophan (99\%) & 0.031 & Ileal digestable threonine & 6.5 \\
\hline Threonine (98\%) & 0.03 & $\mathrm{Ca}$ & 7.2 \\
\hline Palm oil + soybean oil & 3.1 & Total P & 6.1 \\
\hline Molasses & 1.009 & Digestible P & 3.65 \\
\hline \multirow[t]{8}{*}{$\mathrm{NaCl}$} & 0.28 & $\mathrm{Na}$ & 2.5 \\
\hline & & $\mathrm{K}$ & 8.5 \\
\hline & & $\mathrm{Cl}$ & 6.7 \\
\hline & & $\mathrm{Cu}, \mathrm{mg}$ & 20 \\
\hline & & $\mathrm{Zn}, \mathrm{mg}$ & 90 \\
\hline & & Limonene $^{3}$ & 0.010 \\
\hline & & Eugenol $^{3}$ & 0.002 \\
\hline & & Pinene $^{3}$ & 0.0048 \\
\hline Total & 100.00 & $\mathrm{NE}_{f}, \mathrm{MJ} / \mathrm{kg}$ & 10.0 \\
\hline
\end{tabular}

${ }^{1}$ Maiz starch was reduced to $3.96 \%$ in EO; $0.04 \%$ of essential oil mixture was added instead.

${ }^{2}$ This trace mineral-vitamin premix $(0.4 \%)$ supplies per kg diet as follows: vit. A $1750 \mathrm{IU}$, vit. $\mathrm{D}_{3} 200 \mathrm{IU}$, vit. E $11 \mathrm{IU}$, vit. $\mathrm{K}_{1} 0.5 \mathrm{mg}$, vit. $\mathrm{B}_{1} 1.0 \mathrm{mg}$, vit. $\mathrm{B}_{2}$ $4 \mathrm{mg}$, d-pantothenic acid $9 \mathrm{mg}$, niacin $12.5 \mathrm{mg}$ (available), biotin $50 \mu \mathrm{g}$, vit. $\mathrm{B}_{12} 15 \mu \mathrm{g}$, folic acid $0.3 \mathrm{mg}$, vit. $\mathrm{B}_{6} 1.5 \mathrm{mg}$, choline $400 \mathrm{mg}$, Fe $80 \mathrm{mg}, \mathrm{Zn} 54 \mathrm{mg}$, Mn $30 \mathrm{mg}$, Co $0.15 \mathrm{mg}$, I $0.14 \mathrm{mg}$, Se $0.25 \mathrm{mg}$, antioxidants (E310,320,321) $50 \mathrm{mg}$, and maize starch as carrier.

${ }^{3}$ Essential oils in the EO.

countable dilution rate of both parallels were counted, and mean results are given as $\log \mathrm{CFU} / \mathrm{g}$ digesta.

Total genomic DNA was extracted from the digesta samples using DNASpinKit for soil (MPBiomedicals, Heidelberg, Germany) as described by Janczyk et al. [23]. Polymerase chain reaction-denaturing gradient gel electrophoresis (PCR-DGGE) analysis - was employed in order to investigate the changes in the bacterial composition of the intestinal contents. Primer set S-D-Bact-0968-a-S-GC (forward) and S-D-Bact-1401-a-A-17 (reverse) was used [24, 25]. The PCR conditions were as described by Konstantinov et al. [26]. The amplicons of 16S rRNA genes obtained by means of PCR were then separated using DGGE as described by Janczyk et al. [23] with a denaturing gradient of $40-65 \%$. Stained gels with SYBR Gold Nucleic Acid Gel Stain (Molecular Probes, Eugene, Oregon, USA) were exposed to UV light (AlphaDigiDoc RT, Alpha Innotech Corporation, San Leandro, California, USA) for 2 seconds and photographed with a digital camera SP-500 UZ (Olympus, Hamburg, Germany) using AlphaEaseFC Software. The DGGE fingerprints were analysed using BioNumerics software Version 6.0 (Applied Maths, Inc., Sint-Martens-Latem, Belgium).

2.5. Statistical Analyses. Data was analysed using multifactorial model I of ANOVA (Statistica, Tulsa, USA). Effects of age, diet, and farm and diet $\mathrm{x}$ farm interactions were calculated. The Tukey HSD test was used to calculate which differences caused the significant effect of the factors. All results are shown as mean values \pm SD. Differences were considered significant at $P<.05$.

DGGE fingerprints were analysed by calculating the richness (number of bands in a DGGE profile), diversity (Simpson diversity index), and evenness.

Single values were further compared using ANOVA and Tukey HSD tests as mentioned above. Similarity of the DGGE profiles was calculated using the Pearson correlation, and 
it was visualised in a cluster by means of the unweighted pair group method with averaging (UPGMA) applying the BioNumerics.

\section{Results}

3.1. Performance. There were no animal losses during the experiment. Feed intake was recorded for the whole litters only at EF. Individual piglets consumed $240 \pm 149 \mathrm{~g}$ and 200 $\pm 29 \mathrm{~g}$ daily on average in the $\mathrm{C}$ and $\mathrm{EO}$ groups, respectively. Feed conversion ratio was similar in both groups $(1.9 \pm 0.49$ and $2.1 \pm 1.20 \mathrm{~kg} / \mathrm{kg}$ in C and EO, resp.)

Weaned piglets at the experimental farm had better growth performance than piglets at the commercial farm (Figure 1). There were no differences in body weight between the $\mathrm{C}$ and the EO-groups at time of sacrifice.

3.2. Chemical Analyses. SCFA, LA, and ammonia concentrations did not differ between $\mathrm{C}$ and $\mathrm{EO}$ at either farm but were affected by the age. The changes were observed already two days after weaning. The concentration of SCFA in colon increased from $50.8 \pm 14.51$ at 29 days to $86.8 \pm 18.73$ at 30 days and further to $106.8 \pm 19.50 \mathrm{mmol} / \mathrm{L}$ at 39 days $(P<.001)$. LA concentration in distal SI increased from 4.7 \pm 2.21 at 29 days to $24.6 \pm 15.24$ at 30 days and $30.9 \pm 18.87$ $\mathrm{mmol} / \mathrm{L}$ at 39 days $(P=.004)$. Ammonia concentrations in distal SI and in colon decreased from $7.4 \pm 5.36$ and 22.6 \pm 6.90 at 29 days to $5.1 \pm 1.42$ and $16.6 \pm 3.88$ at 30 days and further to $3.5 \pm 1.45$ and $15.7 \pm 3.80 \mathrm{mmol} / \mathrm{L}$ at 39 days, respectively $(P=.003$ and $P<.001)$. These changes were accompanied by $\mathrm{pH}$ changes in the distal SI $(7.4 \pm 0.29$ at 29 days, $6.8 \pm 0.29$ at 30 days, and $6.7 \pm 0.29$ at 39 days, $P<.001)$ and in colon $(6.6 \pm 0.22$ at 29 days, $6.2 \pm 0.26$ at 30 days, and $5.9 \pm 0.27$ at 39 days, $P<.001$ ).

Haptoglobin concentration measured in the serum (group-independent) was $1.7 \pm 1.73$ at $\mathrm{EF}$, while it was 2.7 $\pm 1.95 \mathrm{ng} / \mathrm{mL}$ at $\mathrm{CF}(P<.001)$.

3.3. Microbiological Analyses. The bacterial group and yeast counts in distal SI and in colon are presented in Figures 2, 3 and 4 . Enterobacteria numbers in the intestinal digesta decreased with age (at 39 days) at both farms $(P=.066$ for distal SI, $P<.001$ for colon), with no effect of diet. Enterococci counts in the colon were influenced $(P<.001)$ by farm, age, and diet, while only farm was important for enterococci counts in small intestine. At EF, their number in the gut of weaned piglets was drastically reduced at 33 days and partially recovered at 39 days in the control group, whereas at $\mathrm{CF}$, this phenomenon was observed in the essential oil group. Nevertheless, enterococci counts remained low at 33 days. Small intestinal lactobacilli counts were low at 29 days and increased at 30 days. No effect of diet was observed on bacterial counts in small and large intestine up to 39 days. Yeasts counts in the intestinal digesta increased with age and were also affected by diet and farm $(P<.01)$.

3.4. Denaturing Gradient Gel Electrophoresis. Analysis of bacterial community composition by means of $16 \mathrm{~S}$ rRNA

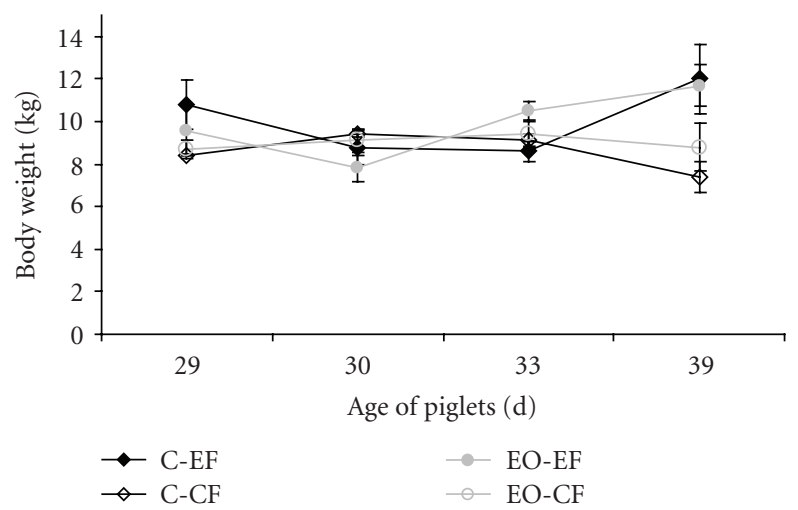

Figure 1: Body weight of piglets 1, 2, 5, and 11 days after weaning that were fed either a diet without $(\mathrm{C})$ or with essential oils (EO) and reared at a commercial (CF) or experimental farm (EF).

PCR-DGGE revealed changes in the bacterial community with age (Figure 4). Whereas the upper bands in the gels from distal SI could be observed in all animals; the bands from the lower part of the gels could be observed first from 30 days, both in CF and EF. No differences in the DGGE patterns between $\mathrm{C}$ and $\mathrm{EO}$ in distal SI could be observed. In colon, however, already the visual analysis of the DGGE profiles revealed a difference between $\mathrm{C}$ and $\mathrm{EO}$ at 39 days, when fewer bands could be observed in the $\mathrm{EO}$ at either farm in comparison to the $\mathrm{C}$ from respective farm. The calculation of richness revealed significant differences between $\mathrm{C}$ and $\mathrm{EO}$ at 39 days (EF: $21 \pm 3.8$ and $5 \pm 1.7, P<.001$; CF: $16 \pm 2.6$ and $7 \pm 1.4, P<.01$ in $\mathrm{C}$ and $\mathrm{EO}$, resp.). This observation was confirmed by clustering of the DGGE profiles of the bacterial $16 \mathrm{~S}$ rRNA gene amplicons from colon digesta which showed distinct clustering of the profiles from piglets at 39 days, independent from the farm. Moreover, the clustering of the profiles using Pearson similarity showed differences between farms (Figure 5).

The Simpson diversity index of the DGGE profiles from the colon bacteria decreased in the EO group at 39 days when compared to $\mathrm{C}$, however, the difference was significant only for EF (EF: $13.1 \pm 1.62$ and $4.6 \pm 2.10, P<.01$; CF: $8.6 \pm$ 1.28 and $4.4 \pm 0.81, P>.05$, resp.). The calculated evenness for the DGGE fingerprints was higher in the EO than in the $\mathrm{C}$ group (in the range of $0.7-1.0$ in $\mathrm{C}$ and $0.6-0.7$ in $\mathrm{EO}$ for the investigated time points at either farm, $P<.001)$. Single diet and age effects could be statistically proven only for the colon bacterial profiles and no difference was observed for ileum digesta samples.

\section{Discussion}

In this study, a mixture of limonene, eugenol, and pinene was fed to weaned piglets but resulted in no effect on piglet production parameters. Performance data, however, were only recorded as descriptive parameters in order to ensure the animals were in overall good condition. Therefore, no final conclusion on the effects of the tested essential oil mixture on piglet performance can be drawn. 


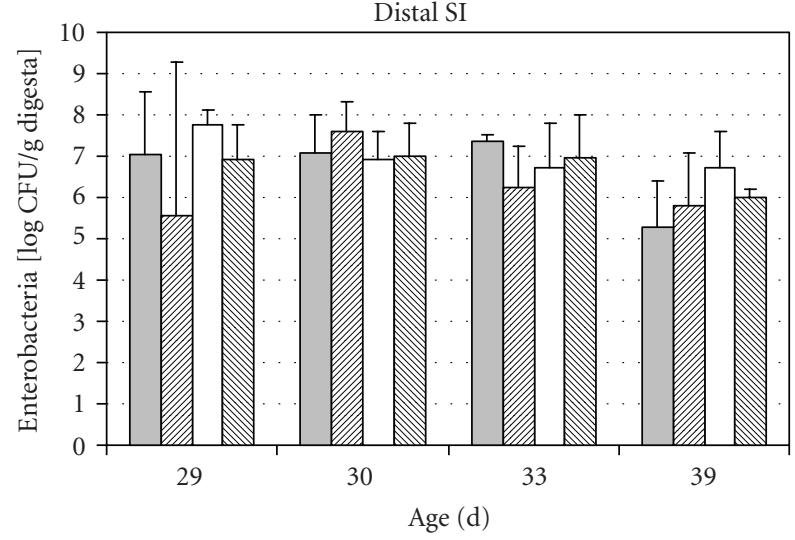

(a)

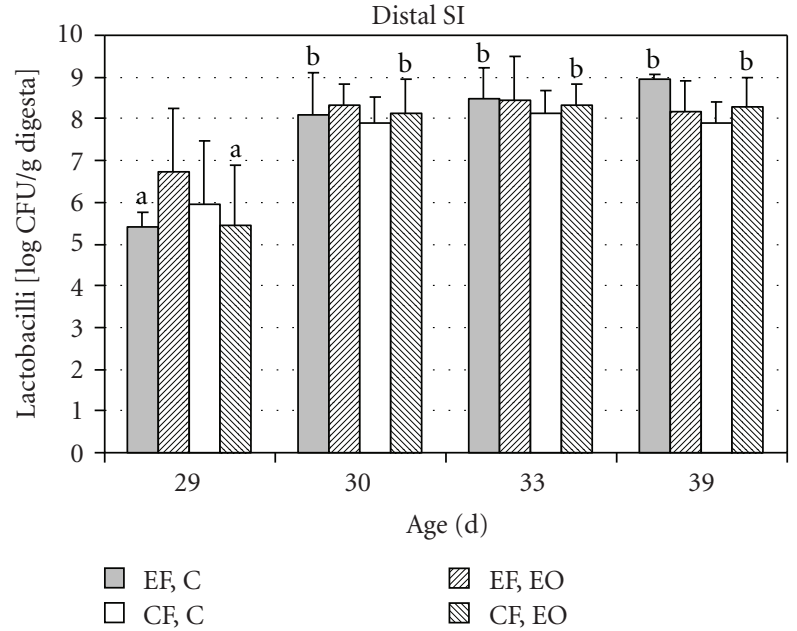

(c)

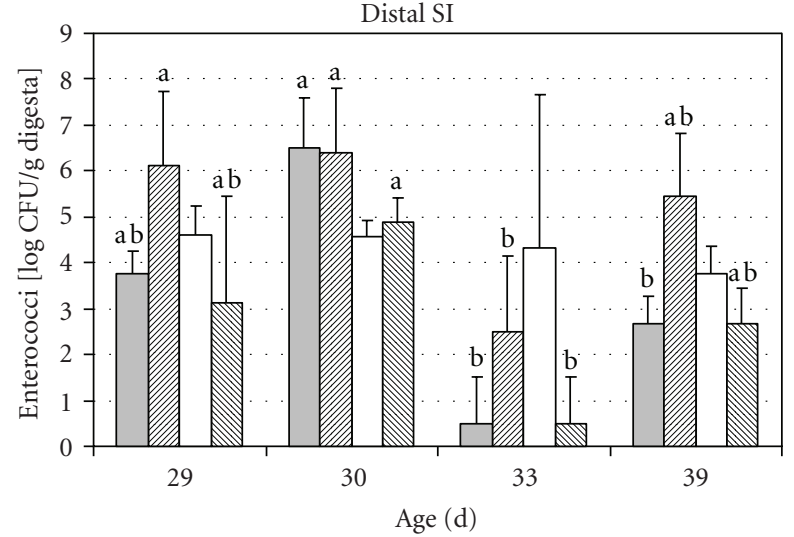

(b)

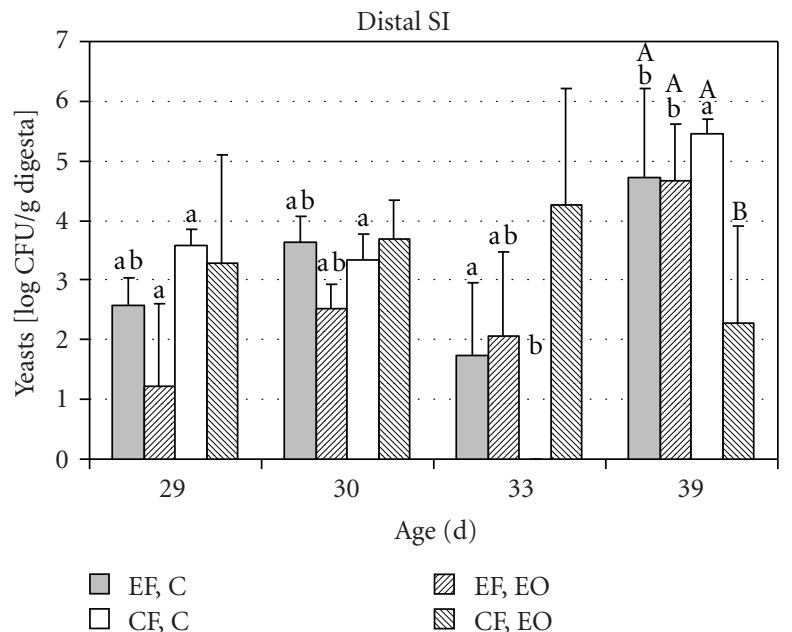

(d)

Figure 2: Bacterial groups and yeasts (log CFU/g) cultivated from distal small intestinal digesta collected at 29, 30 , 33, and 39 day of age from piglets fed after weaning (at 28 days) a starter diet (C) with $0.04 \%$ of essential oils mixture containing limonene, pinene and eugenol. The piglets were reared either at an experimental $(\mathrm{EF})$ of commercial farm $(\mathrm{CF})$. The significant differences $(P<.05)$ between days within one group are marked with different small letters $(a, b)$, and the differences between groups on one day are marked with capital letters $(A$, B). For clarity, only columns that differ are marked.

The choice of conditions (in this case, a farm), where experiments are conducted, can be of importance for observed results. No effects of diet containing in-feed antimicrobials on intestinal microbiota could be observed when an experiment was conducted at a farm with high and constant hygienic conditions [27]. Therefore, the present study was conducted in parallel at two farms, assuming a commercial farm would have lower hygienic conditions because of the lack of a high grade sanitary regime. The hygienic status of the farms was defined "high" (EF) or "low" (CF) according to observations of the farms before the experiment. In the modern EF, built in 2001, five technicians take care of 70 sows. Pens have a plastic grid floor with a solid heated plate in the middle, and they are cleaned 3 times a week with a disinfectant when occupied. By contrast, the more than 45-years-old CF keeps 600 sows and employs 6 technical staff. Pens are provided with concrete floor and when occupied, the faeces are removed from the pens, but cleaning with disinfection only happens when pens are empty. The hypothesis that CF had lower hygienic status was confirmed by measurement of pig serum haptoglobin concentrations. Haptoglobin serum concentration increases in pigs as a result of sequential (although subclinical) infections [28]. As there were no clinical signs of infections in the herd, a higher bacterial and/or viral load at CF could be the reason for the observed results.

Cereal-based starter diets usually contain high amounts of complex plant carbohydrates compared to sow milk. This requires adaptation of intestinal bacteria from fermentation of lactose towards a broad range of carbohydrates. Lactobacilli adapt rapidly to such changes after abrupt decrease in their numbers directly after weaning [23]. In the present study, their numbers in the SIs increased 2 days after weaning. As the main fermentation product of lactobacilli is lactic acid, this may be an explanation for the increase of lactic acid concentration in small intestine. 


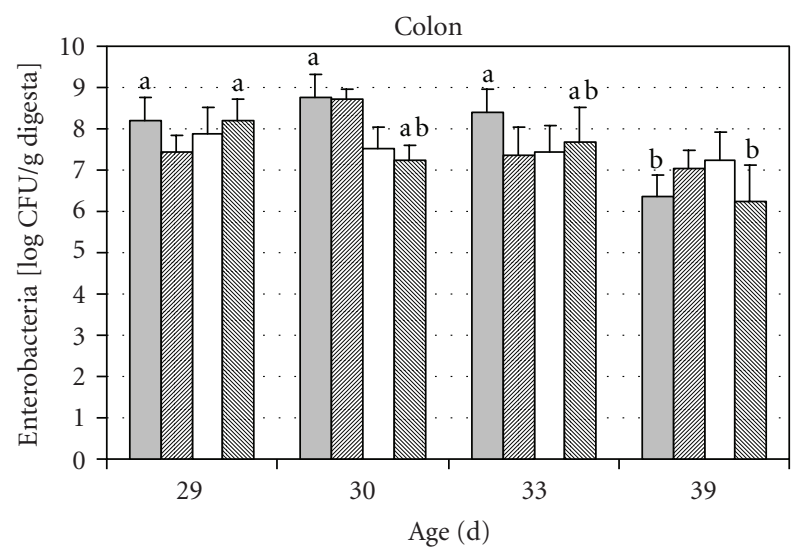

(a)

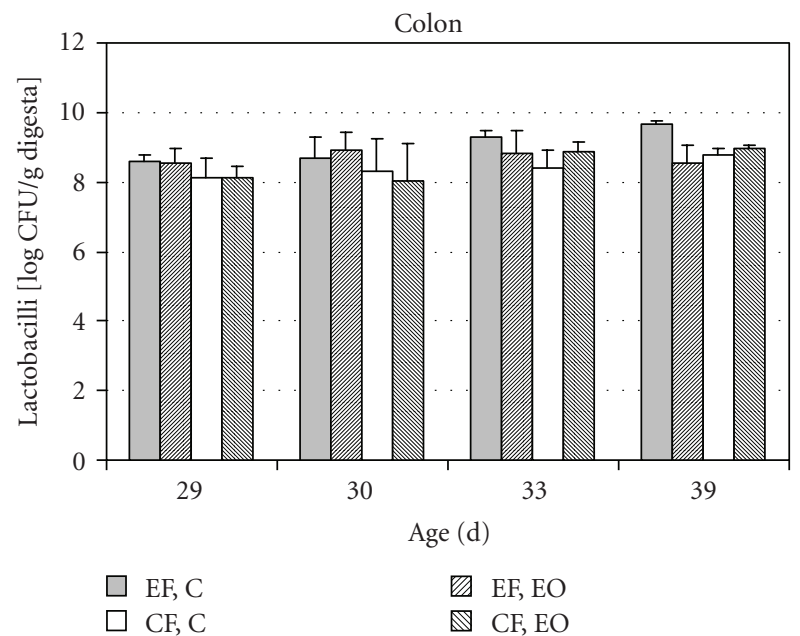

(c)

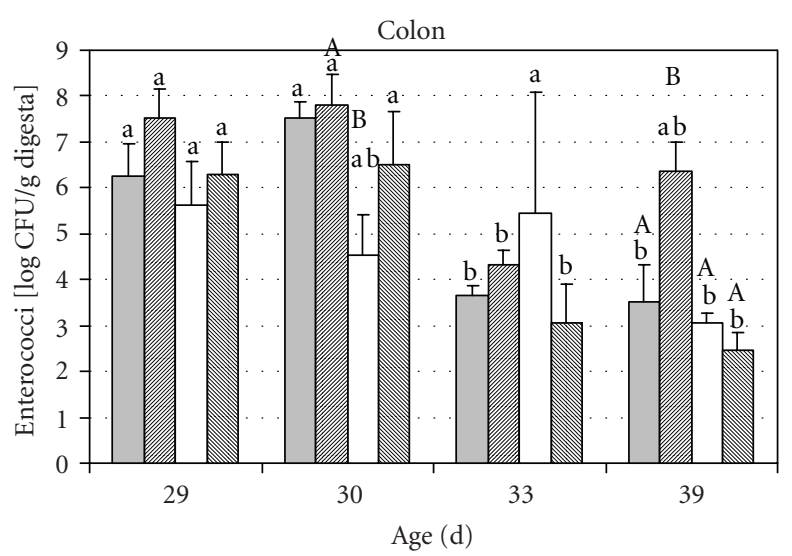

(b)

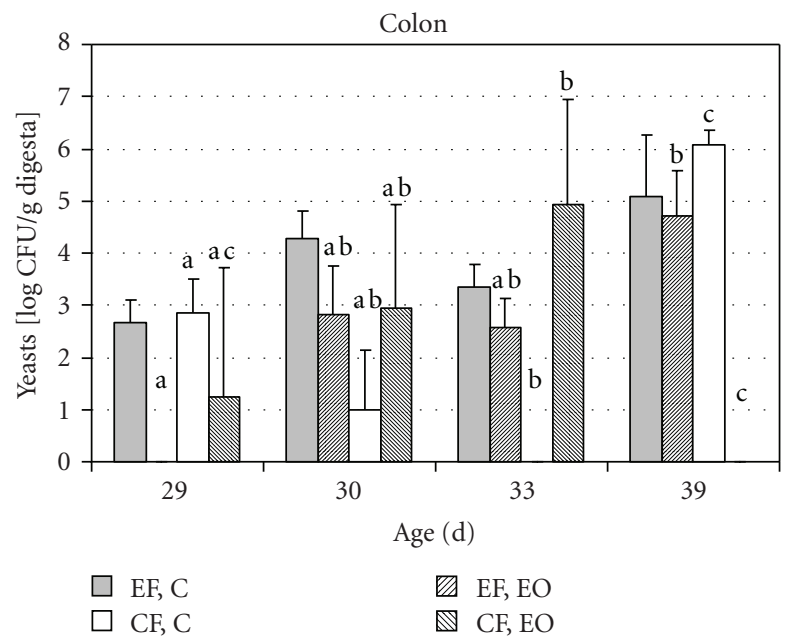

(d)

FIGURE 3: Bacterial groups and yeasts (log CFU/g) cultivated from colon digesta collected at 29, 30, 33, and 39 days of age from piglets fed after weaning (at 28 days) a starter diet (C) with $0.04 \%$ of essential oils mixture containing limonene, pinene, and eugenol. The piglets were reared either at an experimental $(\mathrm{EF})$ of commercial farm $(\mathrm{CF})$. The significant differences $(P<.05)$ between days within one group are marked with different small letters $(\mathrm{a}, \mathrm{b})$, and the differences between groups on one day are marked with capital letters (A, B). For clarity, only columns that differ are marked.

An increase in lactobacilli and the ratio of lactobacilli and enterobacteria in the jejunum and caecum of early weaned pigs, respectively, has been reported at dietary application on carvacrol, cinnamaldehyde, and capsicum oleoresin $[10,11]$. Such an effect, however, could not be found in the present study.

Increased flow of indigestible carbohydrates to the colon results in higher production of SCFA [29]. SCFA in colon increased after weaning, indirectly showing increased feed intake. Ammonia concentration decreased as a result of the higher amounts of starch and other indigestible carbohydrates entering the large intestine, indicating less protein breakdown by indigenous microbiota. These findings correspond with the observed $\mathrm{pH}$ values in both parts of the GIT. All these results confirm earlier observations [27, 3033].

A molecular approach of $16 \mathrm{~S}$ rRNA PCR-DGGE was applied in this study to investigate the changes in the microbial community. Simpson diversity index $\left(S_{1} / D\right)$ and evenness $\left(E_{1} / D\right)$ were adapted and calculated for objective comparison of the DGGE fingerprints' richness (number of bands in a sample). Simpson diversity index is one of the most meaningful and robust diversity measures, and it captures the variance of the species abundance distribution. Its value rises when the assemblage becomes more even. Evenness is a measure of how similar the species are in their abundances and it rises when species are more equally abundant in an assemblage. This parameter is independent from the species richness [34]. At the end of the study, the richness and the diversity of the DGGE profiles were lower in the $\mathrm{EO}$ than in $\mathrm{C}$ at either farm, but significant reduction was recorded only at $\mathrm{EF}$. Bacteria sensitive to active components might have disappeared or their abundance was reduced below the detection limit of the method (being $10^{9}$ cells per g, assuming a total of $10^{11}$ cells in one $g$ of digesta [35]) allowing the remaining bacterial groups a more 


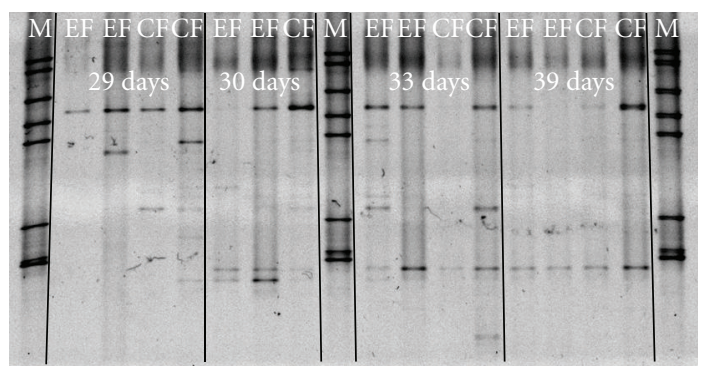

(a)

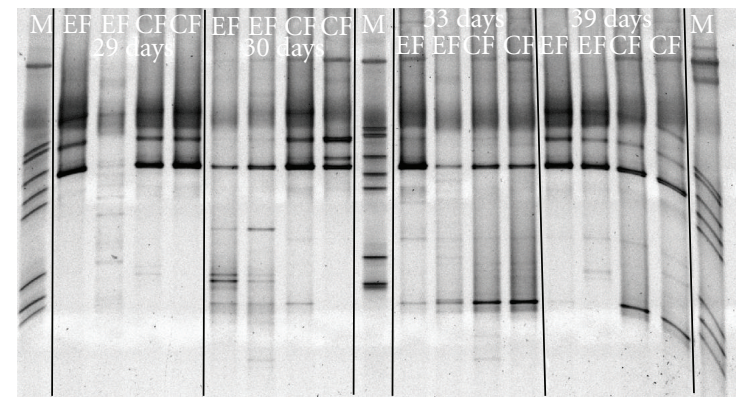

(b)

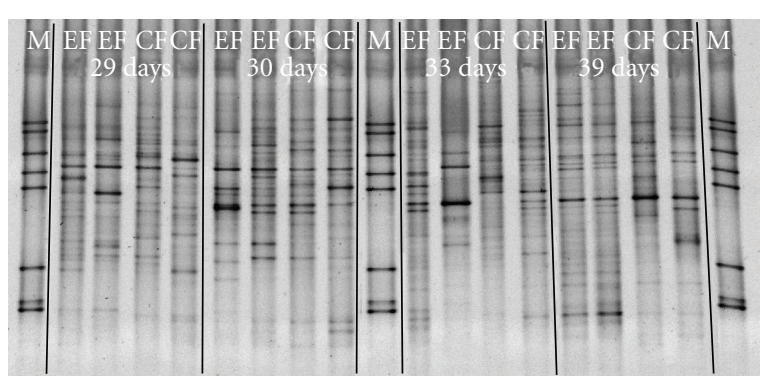

(c)

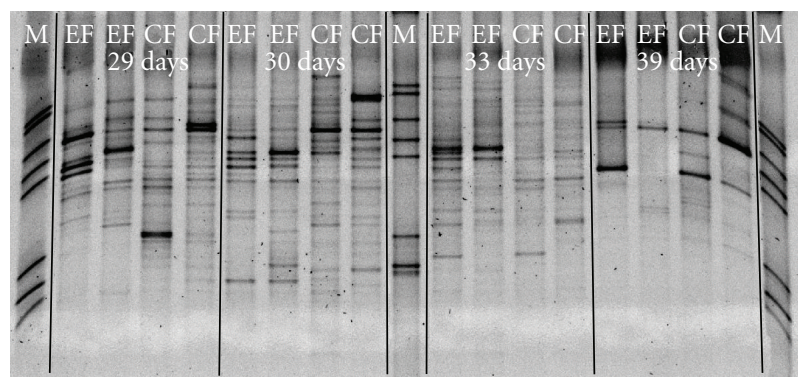

(d)

FIgURE 4: Representative images of denaturing gradient gel electrophoresis fingerprints of amplicons of bacterial V6-V8 fragments of $16 \mathrm{~S}$ rRNA gene obtained from distal small intestinal $(\mathrm{a}, \mathrm{b})$ and colonic (c, d) digesta of piglets fed after weaning a starter diet (a, c) with $0.04 \%$ of essential oils mixture containing limonene, pinene, and eugenol (b, d).

equal development (giving higher evenness). The reduction in the diversity of the colonic microbial population may result in increased susceptibility to diarrhoea of different origin (pathogens, toxins, fatty acids imbalance, etc.); on the other hand, potentially pathogenic bacteria may have also disappeared from the community, as it was recorded for

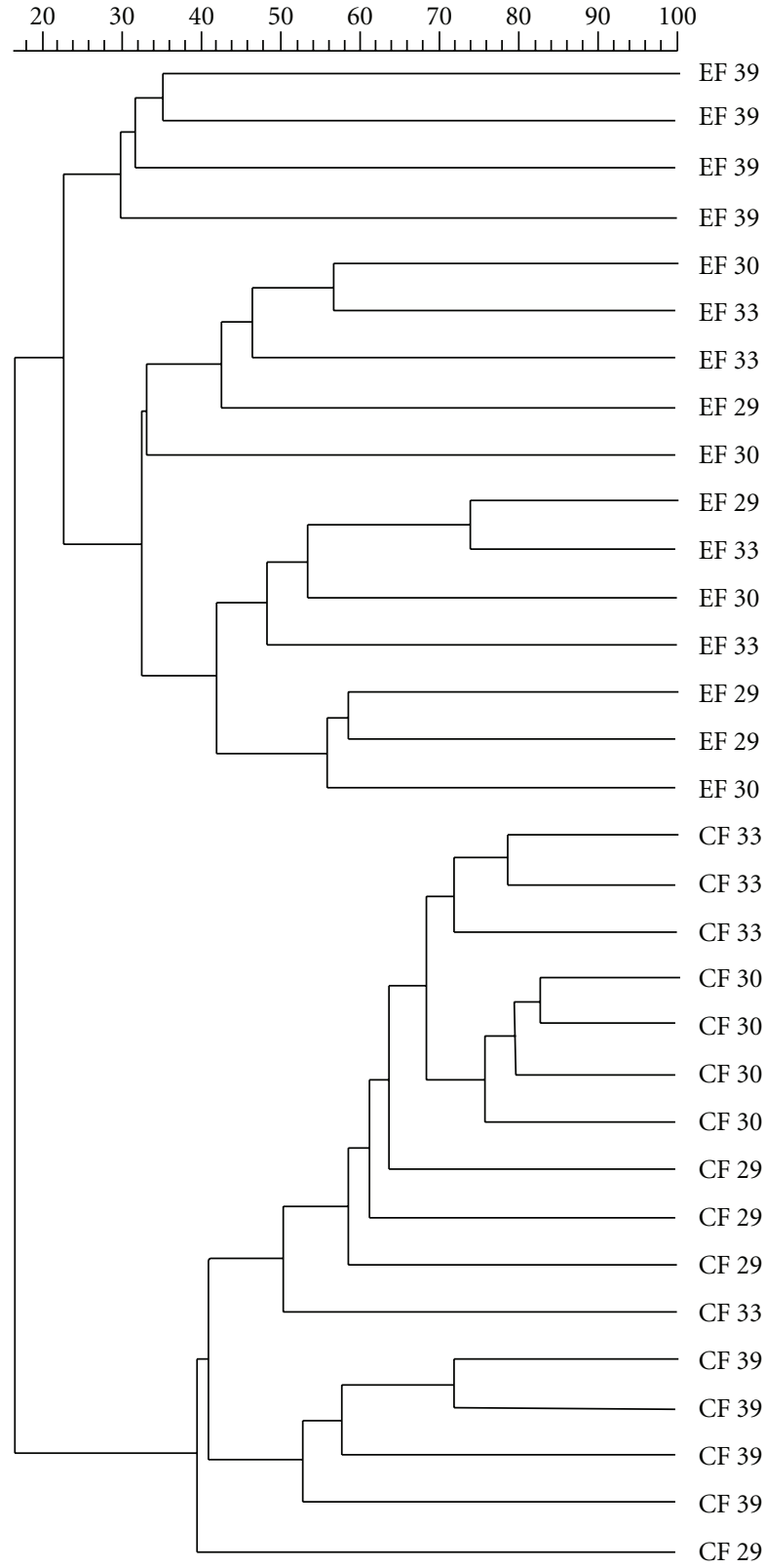

FIGURE 5: Cluster of denaturing gradient gel electrophoresis fingerprints of amplicons of bacterial V6-V8 fragments of 16S rRNA gene obtained from colon digesta of piglets fed after weaning starter diet with $0.04 \%$ of essential oils mixture containing limonene, pinene, and eugenol. Similarity was calculated using Pearson coefficient, and the cluster was formed by means of unweighted pair group method with averaging. EF-experimental farm, CR-commercial farm, 29, 30, 33, 39-age of piglets (d) corresponding to 1, 2, 5, and 11 days after weaning, respectively. Upper bar shows the distance of similarity in \%.

thymol [36]. As we did not sequence the bands in this study, no conclusion can be drawn on which species were affected by the oils mixture and this could be a matter for further studies.

Interestingly, the microbiota in the intestine of the piglets from $\mathrm{CF}$ seemed to be more stable and less affected by the EO 
indicating the importance of the farm. Indeed, the DGGE fingerprints could be clustered individually for each farm, and differences in the intestinal microbial community at each farm could be confirmed. Nevertheless, the general lack of effects of the essential oils on bacterial counts was observed at both farms. However, essential oils reduced the enterococci counts at the commercial farm which was probably depended on the different bacterial loads and on the different initial compositions of the bacterial populations.

Many essential oils have strong antibacterial effects in vitro [6]. However, in vivo results often do not correspond to the findings in vitro $[37,38]$. The reasons for this are unclear, possibly relating to factors such as adsorption time, transit time, or interactions with other digesta components. Sads and Bilkei [39] and Molnar and Bilkei [40] observed positive effects of feeding high levels of essential oils in pig diet (60-180 mg carvacrol and 55-165 mg thymol in kg diet), whereas others observed no effects of feeding low levels of phytogenic products $[10,41,42]$. In a previous study, it was shown that high dosage of thymol ( $10 \mathrm{~g}$ in $\mathrm{kg}$ diet) affected intestinal microbiota in vivo [36]. The dosage applied in the present study was chosen based on concentrations of essential oils commonly used in feed industry and scientific studies [10], which would be economically feasible, and, therefore, the essential oil content $(16.8 \mathrm{mg}$ essential oils per $\mathrm{kg}$ diet) was much lower than in the study of Janczyk et al. [36]. It, therefore, cannot be excluded that certain effects may have occurred at higher dosage of the tested essential oil mixture.

The main aim of the study was to investigate if the tested essential oils provided in economically feasible concentrations had any effects on intestinal parameters in weaned piglets kept under different farm conditions. Individual intestinal bacterial communities were observed at each farm. Limonene, pinene, and eugenol had no overall effect on weaned piglets performance or the gut parameters. However, a late effect of the tested oils could be observed on colon bacterial population composition, and farm conditions seemed to play a role in the observed changes.

\section{Acknowledgments}

The authors would like to thank the European Union for financial support of the project Feed for Pig Health (FOODCT-2004-506144). They would like to thank Anne Koepnick, Indegraud Prignitz, Sonja Bruesch, Brigitte Wuerfel, Marlies Althaus, and Niels Burzan for excellent technical assistance.

\section{References}

[1] D. J. Hampson, "Alterations in piglet small intestinal structure at weaning," Research in Veterinary Science, vol. 40, no. 1, pp. 32-40, 1986.

[2] M. A. M. Spreeuwenberg, J. M. A. J. Verdonk, H. R. Gaskins, and M. W. A. Verstegen, "Small intestine epithelial barrier function is compromised in pigs with low feed intake at weaning," The Journal of Nutrition, vol. 131, no. 5, pp. 15201527, 2001.
[3] G. Boudry, V. Péron, I. Le Huërou-Luron, J. P. Lallès, and B. Sève, "Weaning induces both transient and long-lasting modifications of absorptive, secretory, and barrier properties of piglet intestine," The Journal of Nutrition, vol. 134, no. 9, pp. 2256-2262, 2004.

[4] N. Aligiannis, E. Kalpoutzakis, S. Mitaku, and I. B. Chinou, "Composition and antimicrobial activity of the essential oils of two Origanum species," Journal of Agricultural and Food Chemistry, vol. 49, no. 9, pp. 4168-4170, 2001.

[5] M. Hudaib, E. Speroni, A. M. Di Pietra, and V. Cavrini, "GC/MS evaluation of thyme (Thymus vulgaris L.) oil composition and variations during the vegetative cycle," Journal of Pharmaceutical and Biomedical Analysis, vol. 29, no. 4, pp. 691-700, 2002.

[6] S. Burt, "Essential oils: their antibacterial properties and potential applications in foods-a review," International Journal of Food Microbiology, vol. 94, no. 3, pp. 223-253, 2004.

[7] J. Grassmann, D. Schneider, D. Weiser, and E. F. Elstner, "Antioxidative effects of lemon oil and its components on copper induced oxidation of low density lipoprotein," Arzneimittel-Forschung, vol. 51, no. 10, pp. 799-805, 2001.

[8] A. T. Peana, P. S. D’Aquila, F. Panin, G. Serra, P. Pippia, and M. D. L. Moretti, "Anti-inflammatory activity of linalool and linalyl acetate constituents of essential oils," Phytomedicine, vol. 9, no. 8, pp. 721-726, 2002.

[9] F. A. Santos and V. S. N. Rao, "Antiinflammatory and antinociceptive effects of 1,8-cineole a terpenoid oxide present in many plant essential oils," Phytotherapy Research, vol. 14, no. 4, pp. 240-244, 2000.

[10] E. G. Manzanilla, J. F. Perez, M. Martin, C. Kamel, F. Baucells, and J. Gasa, "Effect of plant extracts and formic acid on the intestinal equilibrium of early-weaned pigs," Journal of Animal Science, vol. 82, no. 11, pp. 3210-3218, 2004.

[11] M. Castillo, S. M. Martín-Orúe, M. Roca, et al., "The response of gastrointestinal microbiota to avilamycin, butyrate, and plant extracts in early-weaned pigs," Journal of Animal Science, vol. 84, no. 10, pp. 2725-2734, 2006.

[12] A. Stoni, K. Zitterl-Egelseer, A. Kroismayr, W. Wetscherek, and W. Windisch, "Tissue recovery of essential oils used as feed additive in piglet feeding and impact on nutrient digestibility," in Proceedings of the 60th Conference of the Society for Nutritional Physiology, Göttingen, Germany, March 2006.

[13] J. H. Cho, Y. J. Chen, B. J. Min, et al., "Effects of essential oils supplementation on growth performance, IgG concentration and fecal noxious gas concentration of weaned pigs," AsianAustralasian Journal of Animal Sciences, vol. 19, no. 1, pp. 8085, 2006.

[14] N. Filipowicz, M. Kamiński, J. Kurlenda, M. Asztemborska, and J. R. Ochocka, "Antibacterial and antifungal activity of juniper berry oil and its selected components," Phytotherapy Research, vol. 17, no. 3, pp. 227-231, 2003.

[15] M. Friedman, P. R. Henika, and R. E. Mandrell, "Bactericidal activities of plant essential oils and some of their isolated constituents against Campylobacter jejuni, Escherichia coli, Listeria monocytogenes, and Salmonella enterica," Journal of Food Protection, vol. 65, no. 10, pp. 1545-1560, 2002.

[16] S. S. Kim, O.-J. Oh, H.-Y. Min, et al., "Eugenol suppresses cyclooxygenase-2 expression in lipopolysaccharide-stimulated mouse macrophage RAW264.7 cells," Life Sciences, vol. 73, no. 3, pp. 337-348, 2003.

[17] T. J. Raphael and G. Kuttan, "Immunomodulatory activity of naturally occurring monoterpenes carvone, limonene, and perillic acid," Immunopharmacology and Immunotoxicology, vol. 25, no. 2, pp. 285-294, 2003. 
[18] C. C. Câmara, N. R. F. Nascimento, C. L. Macêdo-Filho, F. B. S. Almeida, and M. C. Fonteles, "Antispasmodic effect of the essential oil of Plectranthus barbatus and some major constituents on the guinea-pig ileum," Planta Medica, vol. 69, no. 12, pp. 1080-1085, 2003.

[19] M. Reiter and W. Brandt, "Relaxant effects on tracheal and ileal smooth muscles of the guinea pig," Arzneimittel-Forschung, vol. 35, no. 1A, pp. 408-414, 1985.

[20] K. Haacker, H. J. Block, and F. Weissbach, "On the colorimetric determination of lactic acid in silages with $\mathrm{p}$ hydroxydiphenyl," Archiv Tierernährung, vol. 33, no. 6, pp. 505-512, 1983.

[21] E. J. Conway, Microdiffusion Analysis and Volumetric Error, Crosby Lockwood \& Son, London, UK, 5th edition, 1962.

[22] R. Pieper, P. Janczyk, A. Zeyner, H. Smidt, V. Guiard, and W. B. Souffrant, "Ecophysiology of the developing total bacterial and Lactobacillus communities in the terminal small intestine of weaning piglets," Microbial Ecology, vol. 56, no. 3, pp. 474483, 2008.

[23] P. Janczyk, R. Pieper, H. Smidt, and W. B. Souffrant, "Changes in the diversity of pig ileal lactobacilli around weaning determined by means of 16S rRNA gene amplification and denaturing gradient gel electrophoresis," FEMS Microbiology Ecology, vol. 61, no. 1, pp. 132-140, 2007.

[24] U. Nübel, B. Engelen, A. Felsre, et al., "Sequence heterogeneities of genes encoding 16S rRNAs in Paenibacillus polymyxa detected by temperature gradient gel electrophoresis," Journal of Bacteriology, vol. 178, no. 19, pp. 5636-5643, 1996.

[25] A. Felske, A. D. L. Akkermans, and W. M. de Vos, "Quantification of $16 \mathrm{~S}$ rRNAs in complex bacterial communities by multiple competitive reverse transcription-PCR in temperature gradient gel electrophoresis fingerprints," Applied and Environmental Microbiology, vol. 64, no. 11, pp. 4581-4587, 1998.

[26] S. R. Konstantinov, A. Awati, H. Smidt, B. A. Williams, A. D. L. Akkermans, and W. M. de Vos, "Specific response of a novel and abundant Lactobacillus amylovorus-like phylotype to dietary prebiotics in the guts of weaning piglets," Applied and Environmental Microbiology, vol. 70, no. 7, pp. 3821-3830, 2004.

[27] J. Kluess, Evaluation of ileal digesta in weaning piglets fed different diets, Ph.D. thesis, Free University of Berlin, Berlin, Germany, 2004.

[28] H. H. Petersen, J. P. Nielsen, and P. M. H. Heegaard, "Application of acute phase protein measurements in veterinary clinical chemistry," Veterinary Research, vol. 35, no. 2, pp. 163187, 2004.

[29] K. E. Bach Knudsen, A. Serena, N. Canibe, and K. S. Juntunen, "New insight into butyrate metabolism," Proceedings of the Nutrition Society, vol. 62, no. 1, pp. 81-86, 2003.

[30] G. Bolduan, R. Schneider, H. Jung, and B. Klenke, "The ammonia content in the digesta of pigs," Archiv für Tierernahrung, vol. 36, no. 2-3, pp. 281-285, 1986.

[31] K. E. Bach Knudsen, B. B. Jensen, J. O. Andersen, and I. Hansen, "Gastrointestinal implications in pigs of wheat and oat fractions 2. Microbial activity in the gastrointestinal tract," British Journal of Nutrition, vol. 65, no. 2, pp. 233-248, 1991.

[32] A. G. Mathew, T. Jones, and M. A. Franklin, "Effect of creep feeding on selected microflora and short-chain fatty acids in the ileum of weanling pigs," Journal of Animal Science, vol. 72, no. 12, pp. 3163-3168, 1994.
[33] N. Canibe, S. H. Steien, M. Øverland, and B. B. Jensen, "Effect of K-diformate in starter diets on acidity, microbiota, and the amount of organic acids in the digestive tract of piglets, and on gastric alterations," Journal of Animal Science, vol. 79, no. 8, pp. 2123-2133, 2001.

[34] A. E. Magurran, Measuring Biological Diversity, Blackwell Science, Oxford, UK, 1st edition, 2004.

[35] E. G. Zoetendal, A. D. L. Akkermans, and W. M. de Vos, “Temperature gradient gel electrophoresis analysis of 16S rRNA from human fecal samples reveals stable and host-specific communities of active bacteria," Applied and Environmental Microbiology, vol. 64, no. 10, pp. 3854-3859, 1998.

[36] P. Janczyk, P. Trevisi, W. B. Souffrant, and P. Bosi, "Effect of thymol on microbial diversity in the porcine jejunum," International Journal of Food Microbiology, vol. 126, no. 1-2, pp. 258-261, 2008.

[37] W. Si, J. Gong, R. Tsao, et al., "Antimicrobial activity of essential oils and structurally related synthetic food additives towards selected pathogenic and beneficial gut bacteria," Journal of Applied Microbiology, vol. 100, no. 2, pp. 296-305, 2006.

[38] W. Si, J. Gong, C. Chanas, et al., "In vitro assessment of antimicrobial activity of carvacrol, thymol and cinnamaldehyde towards Salmonella serotype Typhimurium DT104: effects of pig diets and emulsification in hydrocolloids," Journal of Applied Microbiology, vol. 101, no. 6, pp. 1282-1291, 2006.

[39] P. R. Sads and G. Bilkei, "The effect of oregano and vaccination against Glässer's disease and pathogenic Escherichia coli on postweaning performance of pigs," Irish Veterinary Journal, vol. 56, no. 12, pp. 611-615, 2003.

[40] C. Molnar and G. Bilkei, "The influence of an oregano feed additive on production parameters and mortality of weaned piglets," Tierarztliche Praxis Ausgabe G, vol. 33, no. 1, pp. 4247, 2005.

[41] S. K. Kommera, R. D. Mateo, F. J. Neher, and S. W. Kim, "Phytobiotics and organic acids as potential alternatives to the use of antibiotics in nursery pig diets," Asian-Australasian Journal of Animal Sciences, vol. 19, no. 12, pp. 1784-1789, 2006.

[42] F. Schöne, A. Vetter, H. Hartung, et al., "Effects of essential oils from fennel (Foeniculi aetheroleum) and caraway (Carvi aetheroleum) in pigs," Journal of Animal Physiology and Animal Nutrition, vol. 90, no. 11-12, pp. 500-510, 2006. 

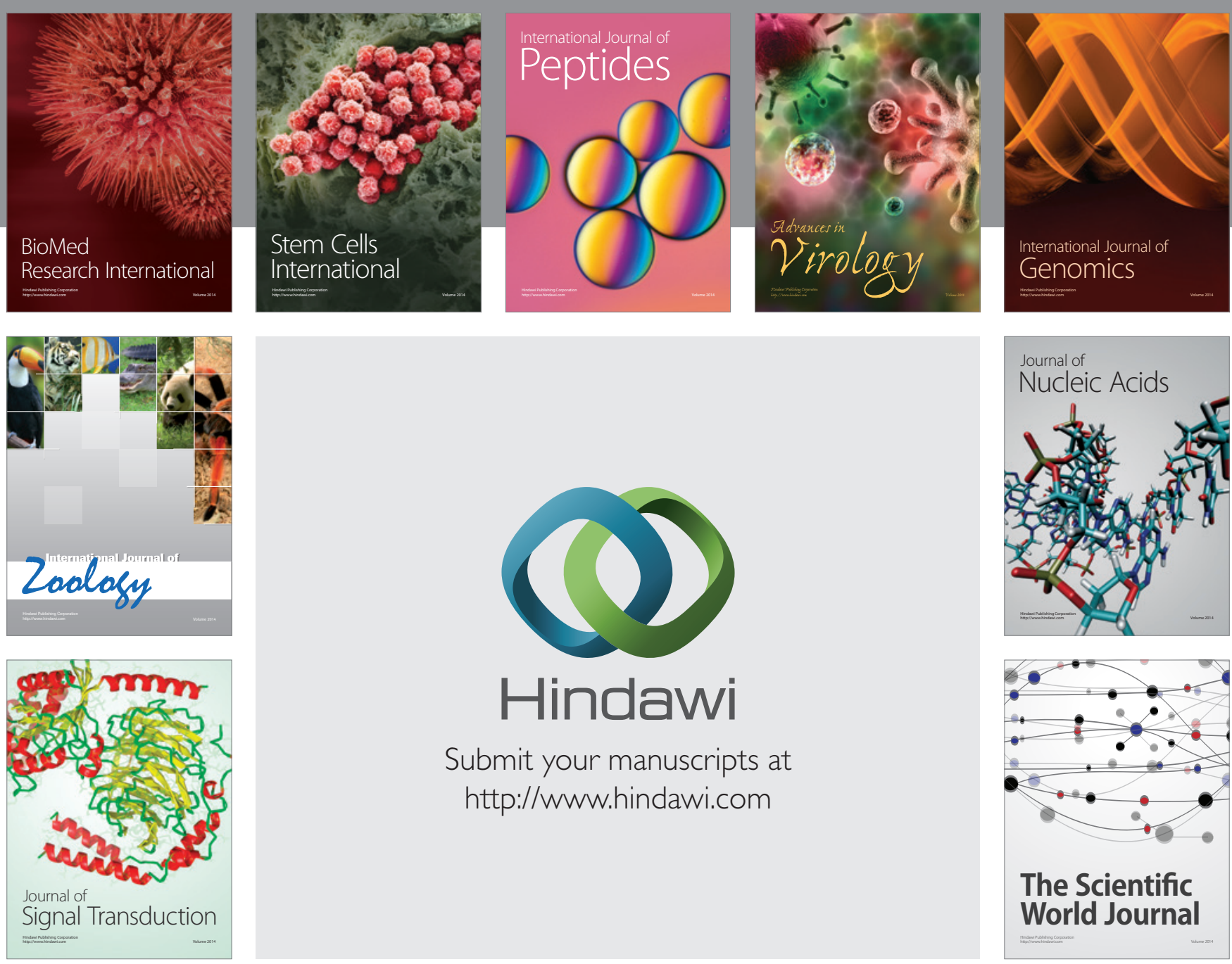

Submit your manuscripts at

http://www.hindawi.com
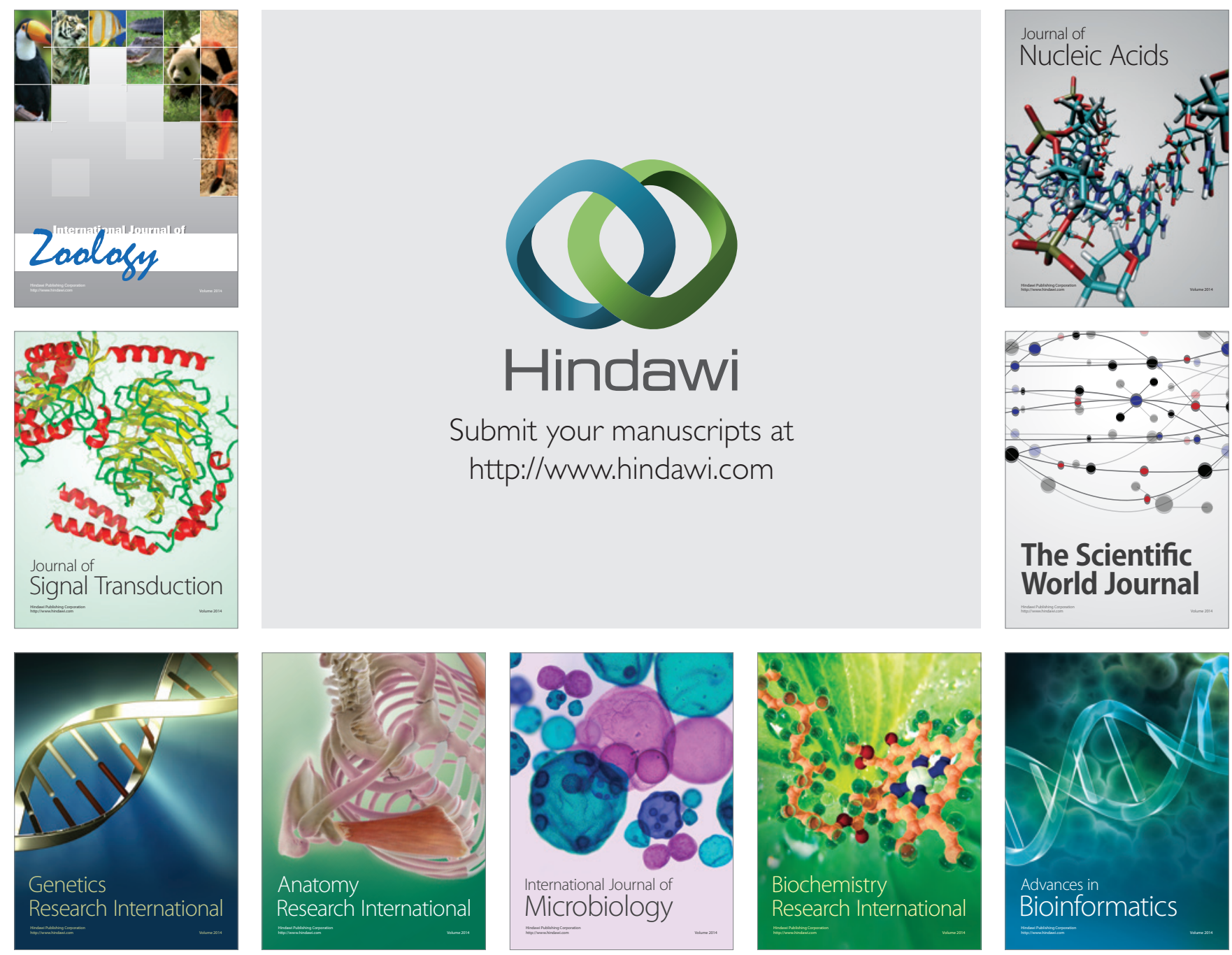

The Scientific World Journal
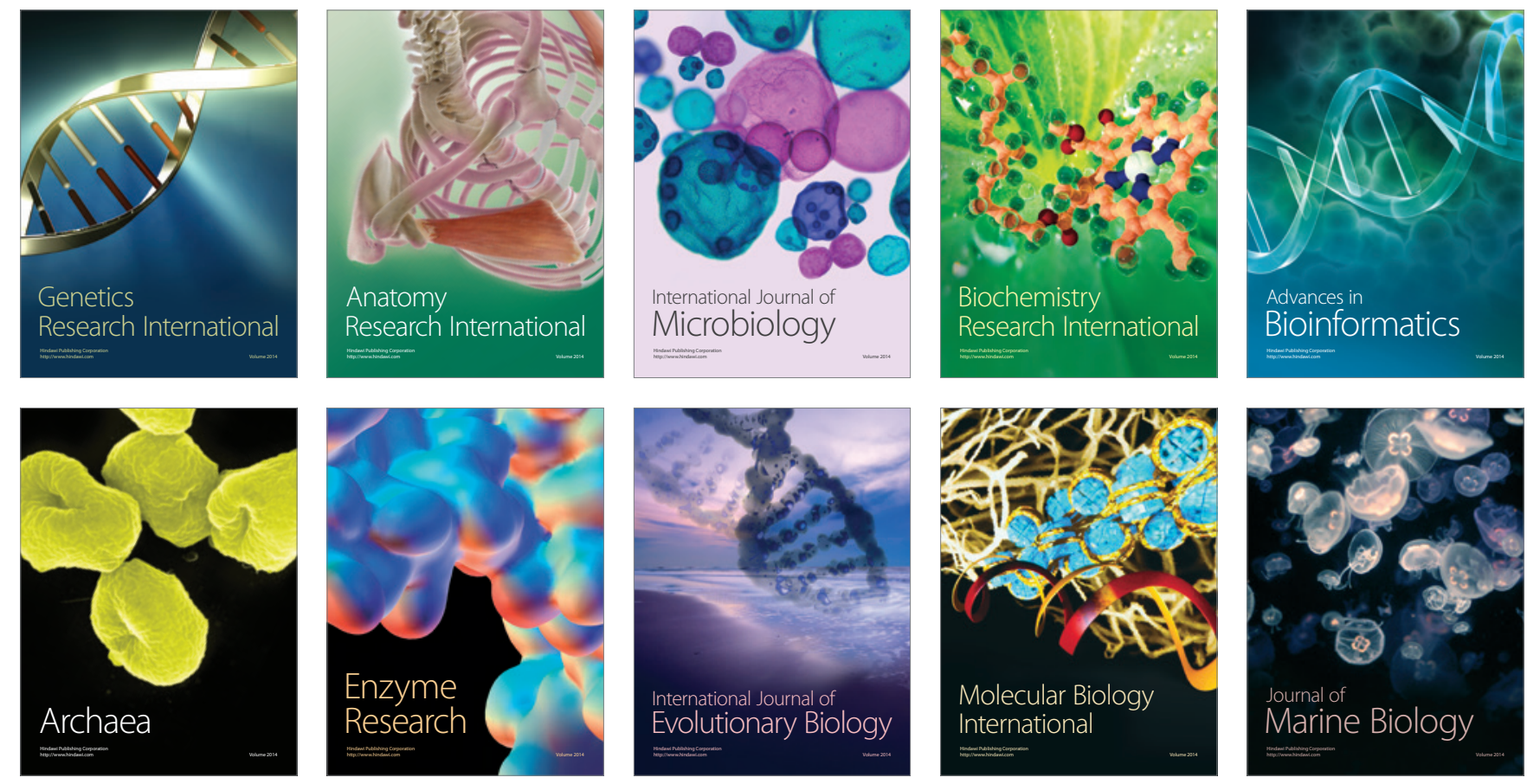